\title{
MUdANÇAS SOCIAIS CONTEMPORÂNEAS \\ E SAÚde: CONSIDERAÇões SObre \\ a Biomedicina e a SAúde Pública
}

Aurea Maria Zöllner Ianni*

\section{Introdução}

Não é possível pensar a sociedade moderna, contemporânea, sem se remeter à ideia de mudança social - um tema genuíno e clássico das ciências sociais - ou, nas palavras de Stompka (2005, p. 13), do "coração da sociologia". Para ele, talvez toda a sociologia seja sobre mudança social. Posteriormente a Stompka, Bauman, conectado a seu tempo, radicalizará a formulação sobre a mudança social, chegando ao conceito de "modernidade líquida" que, segundo ele, se traduz na "convicção de que a mudança é a nossa única permanência" (Bauman, 2011).

Sendo assim, pensar a mudança social indica contingência, podendo indicar também imprecisão, já que o termo expressa os processos em curso no desenvolvimento da história social, sem

\footnotetext{
* Graduada em Ciências Sociais pela Universidade de São Paulo (1980), Mestre (1999) e Doutora (2004) em Ciência Ambiental, e Pós-Doutora pela Universidade Estadual de Campinas (2009). Livre-Docente na área de Ciências Sociais em Saúde pela Faculdade de Saúde Pública da USP (2012). Docente da Faculdade de Saúde Pública da USP e credenciada junto aos Programas de Pós-Graduação em Saúde Pública da Faculdade de Saúde Pública da USP e de Pós-Graduação em Mudança Social e Participação Política da Escola de Artes e Humanidades da USP. E-mail: aureanni@usp.br.
} 
qualquer indicação do que de fato é, ou será; um fenômeno transmutante.

Por isso, somente referidos ao tempo histórico é que se pode pensar, perceber ou identificar as mudanças sociais, as transformações sutis ou marcantes que emergem aqui e ali sob a forma de novos processos, da modificação de valores e de comportamentos, da emergência de novas técnicas e ação política.

Esses fenômenos não ocorrem sem profundas contradições intrínsecas, que se expressam na tensão entre o "novo" e o "velho", o atual e o tradicional e, sobretudo, entre os diferentes atores e sujeitos envolvidos, seus papéis sociais e as instituições estabelecidas.

É importante lembrar, ainda, que fenômenos ou processos sociais que parecem, muitas vezes e num determinado contexto histórico, extremamente transformadores, pouco significarão em outro momento posterior; bem como fatos relegados ou subsumidos numa determinada situação histórica concreta, podem vir a assumir, posteriormente, dimensão significativa no processo social de determinada sociedade. Isto quer dizer que a intencionalidade manifesta dos sujeitos ou atores sociais articula-se à imprevisibilidade dos processos sociais que são, por natureza, abertos, profusos.

Falar de mudança social, portanto, requer sobretudo tentar identificar os pontos críticos das transformações que emergem no desenvolvimento mesmo dos processos histórico-sociais; ou, dito de outra forma, implica identificar as mudanças irreversíveis nas estruturas do social - as diferentes esferas do ordenamento da vida das pessoas, das instituições sociais vigentes, os conflitos políticos em andamento (Bell, 1973).

Nesse sentido, não se trata apenas de especificar as causas ou os efeitos desses fenômenos - o antes e o depois -, mas especialmente de identificar a sua centralidade, o princípio atuante que torna tais fenômenos em realmente transformadores, expressão das mudanças sociais em curso. Essa centralidade, ou princípio atuante, pode sinalizar congruências ou conflitos 
inerentes ao tecido social, bem como movimentos de rotação da sociedade sobre si mesma.

Se tal é a imprevisibilidade dos processos sociais de mudança, perscrutar o real a fim de captá-los, compreendê-los e interpretá-los o quanto possível, dar-lhes atenção, é fundamental para um investigador atento, a fim de "identificar uma 'agenda de questões' com que a sociedade se defrontará e que terão que ser resolvidas" (Bell, 1973, p. 22). E a essa contribuição não se pode furtar, se se pretende produzir um saber práxico, aquele que se propõe conhecer o mundo na perspectiva da sua transformação ou, falando em outros termos, um saber que se articula à ação política (Hobsbawm, 2011).

\section{Algumas transformações que configuram o contemporâneo}

A ideia de "sociedade contemporânea", ou a atribuição do termo contemporâneo à presente fase da moderna sociedade industrial, terá por referência, aqui, sempre, a modernidade tradicional, aquele momento histórico em que a sociedade industrial moderna se configurava, ainda, com as características da plena industrialização, da crença na assertividade da ciência e da tecnologia como expressão da razão e do progresso, da constituição e hegemonia dos estados-nação e do modelo da família nuclear.

Segundo Beck e Lau (2005), apesar das profundas transformações sociais atualmente em curso, todas as sociedades ocidentais ainda guardam suas características modernas, pois não há uma ruptura com relação aos princípios básicos da modernidade, mesmo diante das intensas mudanças que vêm ocorrendo. Daí a sugestão do termo pelos autores: uma segunda modernidade.

Sabe-se que esta segunda modernidade, ou o contemporâneo, como aqui se utiliza, não corresponde a uma etapa de revolução social, mas a um desdobramento, em autorreferência, da tradição 
moderna industrial; a transformação da modernidade por dentro de si mesma (Beck, 2010; Giddens, 1991). Processo que, no entanto, não deixa de promover mudanças estruturais na centralidade das sociedades ocidentais.

O termo "primeira modernidade", longe de consistir uma negação das diferentes fases e impulsos de desenvolvimento da modernização desde as origens da era moderna, pelo contrário, contém o alerta de que a transição para a segunda modernidade marca o ponto final de uma lógica específica de desenvolvimento, uma lógica que, dos meados do século dezenove em diante, tornou-se mais e mais estabelecida na Europa e América do Norte e culminou na ordem do estado-nação e da sociedade industrial na década de 1960. Essa 'alta modernidade' da sociedade industrial foi - como nós mencionamos - caracterizada por uma configuração de instituições que mutuamente confirmavam e davam suporte uma à outra, como o estado-nação, a companhia fordista, a família nuclear, o sistema industrial de relações, o estado do bem estar social e a ciência inquestionável. As fundações dessas estruturas institucionais tinham uma lógica de ordenação e ação que só agora está se tornando clara, somente agora que se trata do seu fim. (Beck; Lau, 2005, p. 527).

Há, também, um outro conceito que se pode aplicar a esse momento histórico, e que muito o caracteriza: o conceito de sociedade pós-industrial, que descortina, especialmente, a centralidade do conhecimento e da informação - produtos da relação entre ciência e técnica - na estrutura social em mudança, e que promovem transformações profundas e correspondentes nas esferas da política e da cultura, desencadeando, dessa forma, novos problemas e desafios para as sociedades (Bell, 1973; Lyotard, 2009). 
Segundo Bell (1973, p. 27):

Os novos modos de vida, que dependem intensamente da primazia do conhecimento cognitivo e teórico, põem inevitavelmente em xeque as tendências da cultura, a qual se empenha em aprimorar o eu e se torna cada vez mais antinômica e antiinstitucional.

Para o autor, o significado de sociedade pós-industrial pode ser melhor compreendido se considerados os seguintes componentes do termo: a mudança de uma economia de produção de bens para uma de serviços, a preeminência de uma classe profissional técnica, a centralidade do conhecimento teórico como fonte de inovação e de política para a sociedade, o controle da tecnologia e da distribuição tecnológica, e o desenvolvimento de novas formas de decisão baseadas na tecnologia intelectual (Bell, 1973).

A seu modo, Lyotard (2009) dirá o mesmo, quando afirma que "o saber tornou-se nos últimos decênios a principal força de produção" e que "sob a forma de mercadoria informacional indispensável ao poderio produtivo, o saber já é e será um desafio maior, talvez o mais importante, na competição mundial pelo poder" (p. 5).

Como se vê, esses autores, ainda nos meados da década de 1970, já identificavam a centralidade das mudanças sociais em curso, nas quais os fluxos do conhecimento científico e técnico vinham consistindo, cada vez mais, em fator estruturante dos processos e relações sociopolíticas e culturais.

Esse fenômeno desdobrou-se nas décadas finais do século XX de forma intensa e exponencial, produzindo uma "virada cultural", segundo expressão de Frederic Jameson referida por Santos (2012); um capitalismo baseado no conhecimento que instrumentaliza, cada vez mais, as culturas, colonizando-as numa espécie de erosão cultural. 
$|46|$

Mudanças Sociais Contemporâneas e Saúde:...

Para Santos (2012), a questão central, hoje, é que, mais do que uma aliança entre capital e ciência, a sociedade atribui à tecnociência a função de motor de acumulação de tudo o que existe, e toma "todo o mundo existente como matéria prima à disposição do trabalho tecnocientífico" (p. 2).

No campo das ciências e práticas de saúde, por exemplo, essa questão tem sido nodal, pois o corpo humano e seus "elementos constitutivos" - membros, órgãos, tecidos, ossos, fluidos etc. - configuram-se, cada vez mais, em matéria prima de produção de novas substâncias medicamentosas, de novas terapêuticas, de práticas de transplantes inter-humanos e interespécies animais, de exercício e experimentação tecnológica, de inoculação de micro-organismos etc.

A virada cultural, para Santos, é também cibernética - uma mudança na lógica sociotécnica -, em que o conceito de informação assume a forma de bytes, genes, micropartículas etc. Microelementos que se tornam, por sua vez, em mecanismos de comunicação e controle das máquinas e dos seres vivos.

Discutindo as formulações de Gilbert Simondon, o autor reafirma o papel central da informação, agora sob a forma de códigos microprocessados que permitem unir todas as substâncias e coisas da natureza, físico-químicas e biológicas. A chave é que essa informação cibernética possibilita uma linguagem comum entre as diferentes áreas do conhecimento científico; o sinal da informação torna-se, portanto, central na produção do viver contemporâneo, e se realiza por meio do conhecimento técnicocientífico - sua produção, distribuição e controle.

E enquanto sinal de informação, esse conhecimento técnicocientífico só adquire sentido na relação emissor-receptor e em contexto sistêmico, ou seja, a informação só se realiza num sistema.

Ocorre que o sinal de informação não é exclusivamente o que deve ser transmitido, mas também o que deve ser recebido, isto é, adquire um sentido, tem eficácia para um todo que tem seu 
próprio jeito de funcionar. Mas tal significado não pode ser encontrado nem na saída nem na chegada: a informação só existe quando o emissor e o receptor do sinal formam um sistema, ela existe entre as duas metades de um sistema disparate até então. A informação é essa aptidão de relacionar que fornece uma resolução, uma integração [...] (Santos, 2012, p. 3).

Isso envolve a produção de uma linguagem comum, uma informação (de)codificável para todos os emissores-receptores que permita articular, sob um mesmo referencial teórico, vários campos do conhecimento científico como o da física, da química e da biologia, sempre por meio, ou na forma, da tecnologia. E essa possibilidade de uma linguagem comum apaga as fronteiras dos objetos físicos, químicos e biológicos, agora integrados em sistemas.

Para a saúde, essa mudança contemporânea é crucial, na medida em que a natureza do corpo biológico passa a ser visto, cada vez mais, como informação. A natureza do corpo biológico, em toda a sua complexidade física e mental, se traduz agora, e cada vez mais, como informação; isto é, o corpo vai sendo paulatinamente exaurido de suas possibilidades materiais complexas, configurando-se crescentemente como microinformação.

Emerge uma contradição: o humano corpo orgânico, complexo, de múltiplas possibilidades materiais, porém exaurido sob o formato informacional, cibernético - de sequências ou quantidades de informação -, vê apagadas todas as suas fronteiras territoriais, todos os olhares disciplinares que o configuraram historicamente, todas as interfaces entre ele e os demais seres vivos, entre culturas.

Nesse sentido, a saúde tem sido, crescentemente, um poderoso e propício campo de problematização sobre essas profundas mudanças sociais em curso, um campo em que a 
informação cibernética pode ser discutida como base do conhecimento sobre a saúde e a doença dos corpos.

Neste trabalho, essa questão será abordada tendo por referência as dimensões da segunda modernidade, pós-industrial, sugeridas por Bell (1973), especialmente as relativas à centralidade do conhecimento teórico como fonte de inovação e política para a sociedade, o controle da técnica e da distribuição tecnológica, e o desenvolvimento de novas formas de decisão baseadas na tecnociência; dimensões estas centrais para o campo da saúde pública ${ }^{1}$, que se estrutura, também, como política pública.

Olhar a produção do conhecimento realizada pela biomedicina, sob esse enfoque, e no contexto das mudanças sociais contemporâneas, permite desnudar algumas das tensões mais relevantes entre esse saber informacional e a saúde pública.

\section{Ciência, Técnica e Informação: a biomedicina e a saúde pública}

No contexto contemporâneo a biologia molecular tem sido, crescentemente, objeto de interesse de pesquisa, desenvolvimento e aplicação no vasto campo que é o da saúde, hoje. A virada cultural cibernética se manifesta de forma evidente e cristalina na saúde, abarcando desde o sequenciamento genético, voltado à identificação dos prováveis desencadeadores, propulsores e fatores causais das doenças, até a indústria farmacêutica, que alardeia, a cada momento, a produção de uma nova droga de cura com base no conhecimento informacional. Há, inclusive, um mercado crescente e em desenvolvimento de uma medicina

\footnotetext{
${ }^{1}$ A saúde pública pode ser entendida como um campo diferenciado do saber em saúde, uma especialidade que se distingue das demais porque se volta para o coletivo, para o bem-estar das populações, envolvendo a promoção, a prevenção e a atenção à saúde, além das ações da vigilância e controle das doenças e produtos prejudiciais à saúde. Mas é também o conjunto das políticas setoriais, programas e práticas do setor saúde, sob gestão e regulação do aparelho de estado.
} 
focada no paciente, no ser individual, na especificidade biofísicoquímica de cada pessoa, com o objetivo da prevenção genética e da proposição de terapêuticas individualizadas. Esse tipo de medicina vem adotando, por exemplo, medicamentos individualizados e intervenções genéticas em fetos ou bebês com vistas à prevenção de prováveis futuras doenças ou degenerações orgânicas.

O termo biomedicina sintetiza a racionalidade da medicina ocidental moderna, um campo de saberes biológicos que envolve instituições e práticas de saúde a ela associadas. Essa racionalidade médica ocidental implica, basicamente, as seguintes proposições de validade: modelos e leis de aplicação geral sobre a doença e o corpo humano, não se ocupando da particularidade dos casos individuais, uma herança do discurso universal da ciência física, que, por sua vez, também ilumina a ideia de corpo máquina, por meio da qual o corpo humano é concebido como conjunto de partes e não como um todo orgânico, merecendo, consequentemente, tratamento fragmentado, a fim de recuperar seu pleno funcionamento (Camargo Jr, 1997).

Sarti (2010), na mesma linha de argumentação, diz que a biomedicina se constitui como o campo que "tem o domínio da concepção de vida e de morte na sociedade ocidental contemporânea" (p. 78), tendo se tornado "a referência internalizada (inconsciente, portanto) para os cuidados de nossas próprias dores e sofrimentos" (p. 81). Segundo a autora:

Quando se trata de estudar o corpo, a saúde e a doença, o objeto de investigação torna-se, direta ou indiretamente, o próprio campo científico que produz a verdade sobre o que é o corpo, a saúde e a doença no mundo ocidental, ou seja, a biomedicina e seus agentes. (Sarti, 2010, p. 79).

Para Teixeira (2012, p. 322), diferentemente, a noção de biomedicina é aquela "empregada para designar o processo iniciado depois da Segunda Guerra Mundial de articulação entre biologia, medicina, ciência, tecnologia, inovação e rotinas". 
Como se pode ver, o termo biomedicina, seja ele referido aos domínios e proposições de validade sobre o corpo, sua saúde ou doença, seja ele referido ao desenvolvimento histórico da ciência e da técnica biomédicas no século $X X$, diz respeito a um campo no qual a tecnociência encontra solo propício à fertilização. Aí, a concepção informacional, cibernética dos viventes manipulados através dos genes, dos micro-organismos e partículas - encontra espaço de plena realização.

Tal como nos demais processos sociais, na saúde também a informação microprocessada vem construindo uma linguagem comum entre as diferentes disciplinas científicas do campo e suas inúmeras profissões, protagonizando uma conexão sistêmica entre produção de conhecimento, sua distribuição e controle no âmbito da sociedade, criando, dessa forma, cultura.

Nunes (2001), ao estudar a investigação biomédica na oncologia $^{2}$ (ou cancerologia), mostra como por trás dessa tradução informacional - sistêmica e padronizada - ocultam-se invisibilidades que produzem procedimentos diferenciados sobre como agir em relação aos processos de saúde-doença das diferentes populações. Segundo ele, muitos dos estudos que vêm sendo desenvolvidos no âmbito dos laboratórios de microbiologia merecem atenção, já que essas invisibilidades têm sido ignoradas ou secundarizadas, comprometendo a aplicabilidade do conhecimento em prol de uma melhora, real, da situação de saúde das populações envolvidas.

Para ele, a maior parte das etnologias sobre laboratórios

Parece[m] assentar no pressuposto de que, uma vez estabelecidos laboratórios com infra-estruturas, pessoal e equipamentos adequados, ou - para utilizar a linguagem da teoria dos atores-redes

\footnotetext{
${ }^{2}$ Esse trabalho do autor, aqui utilizado, tem por objeto a problematização das etnografias de laboratórios internacionais que realizam estudos genéticos sobre a natureza do câncer no campo da biologia molecular.
} 
(Latour, 1987; Law e Hassard, 1999) - uma vez que o laboratório tenha sido replicado ou "transportado" a partir, por exemplo, dos Estados Unidos ou da Alemanha para o Brasil, Portugal ou Japão, quaisquer diferenças que permanecerem poderão ser atribuídas, seja a uma variabilidade entre locais do mesmo tipo da que é detectável entre laboratórios situados no centro ou a diferentes condições no que respeita à relação do laboratório com o seu ambiente 'externo' [...]. (Nunes, 2001, p. 36) ${ }^{3}$.

O ambiente externo, na acepção de Nunes, diz respeito às orientações da política científica conforme os diferentes países, às prioridades de financiamento e condições econômicas impostas pelas realidades locais, ao sistema educativo que produz diferentes sujeitos e culturas científicas e de informação, ao vínculo entre as instituições de investigação e os governos e/ou segmentos privados, e também, à divisão sexual do trabalho nos diversos países e regiões, além de exclusões de classes sociais, de raça e étnicas.

Segundo ele, essas questões, determinantes nos processos de produção e vida intelectual dos laboratórios, tenderam, sempre, a ser tratadas como exteriores a eles. E ressalta que é preciso observar como essas variações loco-regionais condicionam cada um dos laboratórios organizados segundo os critérios dominantes padronizados (e padronizadores) da ciência ocidental; alertando para o fato de que há invisibilidades que "são mediadas por diferenças nos meios sociais e culturais locais e nacionais em que os laboratórios se situam, em função da posição destes no sistema mundial da ciência" (Nunes, 2001, p. 37).

Essas são diferenças que fazem toda a diferença. Há, portanto, um paradoxo teórico no sistema global da informação

\footnotetext{
${ }^{3}$ As referências no texto de Nunes aos autores da teoria dos atores-rede são: Latour, Bruno (1987). Science in Action. Miçton Keynes: Open University Press; e Law, John e Hassard, John (1999). Actor Network Theory and After. Oxford: Blackwell.
} 
cibernética produzida pela grande ciência: o conhecimento codificado em informação pela lógica sociotécnica predominante apaga todas as fronteiras territoriais, disciplinares, e entre os seres vivos e as culturas, ao mesmo tempo em que o palco dessa produção sociotécnica é condicionado pelas "externalidades" e "invisibilidades" socioculturais presentes na vida dos diferentes laboratórios, conforme os diferentes países e contextos locoregionais.

É claro que quanto mais aproximada da definição molecular, mais viável a translocalização e a transnacionalização dos resultados das pesquisas, o que amplia as possibilidades de uma articulação sistêmica global.

Porém, mesmo na dimensão microinformacional considerada extremamente padronizável, e portanto segura enquanto mercadoria informacional, é possível pensar, a partir da formulação de Lewontin (1991), que não há ambiente "exterior" num sentido independente e abstrato. Para o autor, assim como não há organismos sem ambiente, não há ambiente sem organismos, já que os organismos constroem seu próprio ambiente, destroem-no, modificam-no, transformam-no e intervêm, numa relação dialética de parte e todo, do particular e do geral. Na esfera da microbiologia esse fenômeno ficou claro quando, após os primeiros e propagados êxitos sobre o sequenciamento genético, verificou-se que o papel das proteínas na determinação das características e comportamentos dos genes dos indivíduos é igual, ou superior, ao próprio gene em si, e que este só se realiza na interação com as mesmas.

Outro aspecto importante das invisibilidades desses processos laboratoriais, e que merece ser aqui mencionado, é o fato de que a biologia vem se deparando, atualmente, com um problema relevante, que é o fato dela trabalhar com variáveis que em grande parte são impossíveis, na prática, de medir valores (Blanc, 1991). Um dilema que atinge também a microbiologia.

Segundo Nunes (2001), há alguns cânceres que ocorrem nomeadamente em populações de sociedades periféricas, 
marginalizadas ou excluídas, e outros tipos deles ocorrem, geralmente, em populações das sociedades centrais e de grupos dominantes, indicando que muitas doenças podem ser consideradas como relacionadas a condições locais particulares. Isso mostra que as informações cibernéticas podem conter informações aproximadas, e não propriamente exatas, como creem muitos cientistas, tomado o universo informacional padronizado, mercantilizado.

Tais paradoxos, com certeza, se refletem nos resultados encontrados, ainda que estes sejam secundarizados ou invisibilizados pela tecnociência da saúde.

Referindo-se ao caso português, Nunes (2001) diz que

Embora tenham sido identificados e estudados fatores genéticos na iniciação e promoção do carcinoma gástrico, estamos perante um tipo de câncer fortemente associado à exposição a influências ambientais, nomeadamente a dieta alimentar e as substâncias químicas utilizadas em alimentos. Uma outra influência é a da infecção endêmica de mais de $80 \%$ da população portuguesa (segundo os estudos existentes) pela bactéria Helycobacter Pylori, que aumenta a susceptibilidade individual a doenças gástricas e, em particular, ao carcinoma gástrico. (Nunes, 2001, p. 56).

O autor menciona, ainda, o fato de que "esse domínio de investigação tende a articular-se de maneira particularmente densa com os contextos locais da prática clínica e da atividade de prevenção" (Nunes, 2001, p. 42), o que vincula, inexoravelmente, a biomedicina às práticas e ações de saúde pública.

E ainda, como bem nos lembra o autor, sujeitos ou pacientes (e sua sujeição aos testes laboratoriais) são indispensáveis aos procedimentos clínicos de coleta de material para a realização das análises dos grandes laboratórios de biologia molecular. Uma etapa fundamental para que pesquisadores tenham acesso ao material biológico humano indispensável aos procedimentos in 
vitro. A remoção de fluidos, tecidos e órgãos humanos para análise relocalizam, por isso, a demarcação entre corpo e ambiente, neste caso, entre micro-organismos e corpos biológicos.

\begin{abstract}
A seqüência de procedimentos usados pelos investigadores para lidar com os materiais biológicos recolhidos é inseparável das sucessivas redefinições da demarcação entre o corpo e o ambiente ou entre o organismo e o ambiente in vitro. Para cada procedimento é criado um ambiente adequado, através do recurso a instrumentos, a materiais biológicos e químicos e a intervenções humanas, de modo a evitar decomposição precoce, a contaminação ou a modificação não controlada das amostras, e a maximizar a sua subordinação às exigências de cada procedimento. (Nunes, 2001, p. 66-67).
\end{abstract}

O elo entre esse segmento laboratorial da tecnociência biomédica e a saúde pública pode ser reconhecido de diversas formas. Por exemplo, a priorização do estudo de certos tipos de doenças como alguns cânceres muitas vezes obedece ao perfil epidemiológico da população-alvo, isto é, atende a critérios de prioridade em saúde pública - quando a doença é prevalente na população, ou quando se incentiva a investigação de uma doença que tem sido negligenciada por estudos promovidos pelos interesses das grandes corporações produtivas, como a indústria farmacêutica, focada apenas no mercado consumidor. Outras vezes, é o próprio sistema público de saúde que oferece o campo de estudos por meio dos serviços instalados e das populações neles atendidas - como o caso da inovadora e exitosa política de prevenção e controle da epidemia de AIDS no Brasil, que para além das estratégias relativas ao acesso, organização e gestão dos serviços de assistência aos vulneráveis, susceptíveis e soropositivos, articularam-se estratégias de pesquisa e ensino. Isto, quando se considera indispensável e crucial o enfrentamento de uma determinada doença. 
É importante lembrar, ainda, que vários laboratórios e institutos estatais, no caso do Brasil, estão imersos nas pesquisas tecnocientíficas. Há, por exemplo, as fundações Manguinhos e Osvaldo Cruz no Rio de Janeiro, e os Institutos Butantan, Adolfo Lutz e Pasteur em São Paulo, que desenvolvem pesquisas dessa natureza. E a EMBRAPA (Empresa Brasileira de Pesquisa Agropecuária), que desenvolve pesquisas de alimentos fortificados geneticamente, numa interface com o campo da nutrição em saúde pública.

Fica evidente com isso que não se pode desconsiderar as particularidades, aquelas da vida intelectual e produtiva dos laboratórios e nem mesmo o perfil sociocultural das populações. E todos são componentes que vinculam a biomedicina à saúde pública, numa teia de receptores-emissores dos sinais de informação e dos ambientes externos e internos de produção e manipulação dessas informações.

\section{Considerações finais}

No contexto da segunda modernidade, o da sociedade informacional, a cibernética é um dos elos pelos quais a biomedicina se vincula à saúde pública já que os seus objetos informacionais estão relacionados à situação de saúde das populações, e seus achados serão, oportunamente, objeto de uso e aplicação, tanto no âmbito da prática clínica como no da prevenção de doenças, traduzidas nas políticas e ações públicas de saúde. Nesse sentido, a tecnociência biomédica penetra e condiciona, cada vez mais, a esfera do cuidado do sofrimento humano, das pessoas e populações, internalizando nos corpos dos indivíduos a intervenção informacional, configurando toda a política.

A redução de escala do objeto - sob a forma de bytes, genes, micropartículas etc. - possível com a redução da abordagem teórica, cibernética, tem sido crucial para estabelecer vínculos entre os polos tecnocientíficos globais, ultrapassando os limites do local 
e do regional. A informação como aptidão de relacionar, como integração cujo significado não está nem na saída nem na entrada do sistema de informação também existe no campo da saúde.

No entanto, essa constituição sistêmica da informação pressupõe a eliminação da "influência 'perturbadora' de fatores associados aos organismos que constituem obstáculos à padronização da informação" (Nunes, 2001, p. 59).

Na perspectiva da tradução da informação, definida como uma prioridade no mundo da ciência global, desterritorializada, desincorporada, padronizada e transportável, a biomedicina se ajusta como uma luva em função das suas proposições de validade - a do discurso universal herdado da ciência física que não se ocupa da particularidade dos casos individuais e a ideia do corpo máquina concebido como conjunto de partes, agora cada vez mais diminutas, microinformacionais.

E essa prática, a da centralidade do conhecimento teórico informacional como fonte de inovação e de política, se estabelece não apenas pelo controle e distribuição da tecnologia articulados ao desenvolvimento de novas formas de decisão, mas amplia a política por meio do controle e distribuição do (potencial) poder de cura, agora internalizado nos corpos dos indivíduos e das populações. A biopolítica de Foucault (Machado, 1993) se microesfacela nos corpos biológicos e suas informações, paradoxalmente, universalizado por meio dos estudos laboratoriais globais.

Cria-se uma dinâmica social contraditória, que integra desintegrando, produz uma linguagem teórica mundializada particularizando.

\section{Bibliografia}

BAUMAN, Z. "A face humana da sociologia" (entrevista a Laura Greenhalg). Jornal O Estado de São Paulo. 30 de Abril de 2011, p. S4. 
BLANC, M. Os Herdeiros de Darwin. Trad. Mariclara Barros. Lisboa: Editorial Teorema, 1991.

BECK, U. Sociedade de Risco. Rumo a uma outra Modernidade. Trad. Sebastião Nascimento. São Paulo: Editora 34, 2010.

BECK, U.; LAU, C. "Second modernity as a research agenda: theoretical and empirical explorations in the 'meta-change' of modern society". The British Journal of Sociology, Volume 56, Issue 4, 2005.

BELL, D. "Introdução". In: O Advento da Sociedade Pós-industrial. Uma Tentativa de Previsão Social. Trad. Heloisa de Lima Dantas. São Paulo: Editora Cultrix, 1973, p. 15-62.

CAMARGO JR, K. R. Biomedicina, Saber \& Ciência: uma Abordagem Crítica. São Paulo: Editora HUCITEC, 2003.

GIDDENS, A. As Conseqüências da Modernidade. Trad. Raul Fiker. São Paulo: Editora UNESP, p. 43-51, 1991.

HOBSBAWM, E. Como Mudar o Mundo. Marx e o Marxismo. Trad. Donaldson M. Garschagen. São Paulo: Companhia das Letras, 2011.

LEWONTIN, R. C. Biology as Ideology. The Doctrine of DNA. New York: Harper Collins Publishers, 1991.

LYOTARD, J. F. Capítulo 1 "O campo: o saber nas sociedades informatizadas". In: A Condição Pós-Moderna. Trad. Ricardo Corrêa Barbosa. Rio de Janeiro: José Olympio, 2009, p. 3-10.

MACHADO, R. "Introdução. Por uma genealogia do poder". In: FOUCAULT, M. Microfísica do Poder. Trad. Roberto Machado. Rio de Janeiro: Edições Graal Ltda. , 1993, p. viixxviii.

NUNES, J. A. Capítulo 1 "Laboratórios, escalas e mediações na investigação biomédica. A oncobiologia entre o global e o local". In: NUNES, J. A. e GONÇALVES, M. E. (orgs). 
Enteados de Galileu? A Semiperiferia no sistema Mundial da Ciência. Porto: Afrontamento, 2001, p. 33-75.

SANTOS, L. G. "Predação high tech, biodiversidade e erosão cultural: o caso do Brasil". 23 pgs. Disponível em: <http:// www.ifch.unicamp.br/cetme/txt/predacao.pdf $>$. Acesso em: 14 set. 2012.

SARTI, C. "Corpo e Doença no trânsito de saberes". Revista Brasileira de Ciências Sociais, v. 2, n. 74, p. 77- 191, out. 2010.

SZTPOMPKA, P. "Prefácio". In: A Sociologia da Mudança Social. Trad. Pedro Jorgensen Jr. Rio de Janeiro: Civilização Brasileira, 2005, p. 13-17.

TEIXEIRA, M. O. “Plataformas Tecnológicas e as práticas de pesquisa em biomedicina - observações preliminares sobre o uso de dispositivos globais e instituições locais". Sociologias, Porto Alegre, ano 14, n. 29, p. 312-336, jan./abr. 2012. 